\section{Errantes, Erráticos,}

\section{Errabundos: performador como} errante urbano, performance como errância urbana

\author{
Diego MARQUES ${ }^{1}$
}

\section{Resumo}

Como desdomesticar a relação corpo e cidade? A partir desta questão o presente artigo procura realizar uma leitura crítica das implicações éticas, estéticas e políticas da experiência corporal urbana contemporânea. Para tanto, propõe o artista da performance como errante urbano e a arte da performance como errância urbana.

Palavras chave: corpo, performance, cidade.
1.

Performer, graduado em Comunicação das Artes do Corpo pela PUC-SP e mestrando em artes no IA da UNESP. É integrante do Coletivo Parabelo através do qual pesquisa relações entre corpo, performance e cidade desde 2005. E-mail diegoalvesmarques@hotmail.com 
O que seria a união entre ética e estética, sem a política, senão uma exaltação do indivíduo? Como se arriscar na associação entre a estética e a política, sem a ética, depois da terrivel experiência nazista? Por que insistir na relação privilegiada da política com a ética, sem a estética, após o enfado dos últimos anos na trajetória da esquerda? Tatiana Roque

"Tenho muito o que fazer. Preparo o meu próximo erro." Bertold Brecht

Uma história de performance

$\mathrm{Ou}$

Uma história solta, Uma história pipa. ${ }^{2}$

Um homem com traje social amarra uma corda no colarinho de sua camisa e lança-a em meio aos corpos de passagem pelo centro de São Paulo. Três crianças se aproximam, puxam a corda e levam o homem para passear pela rua Direita, em seguida, tentam adestrá-lo. Vendedores ambulantes intervêm. Crianças, ambulantes e transeuntes discutem o paradeiro daquele homem. Juntos questionam o papel da polícia militar nas ruas do centro de São Paulo. Crianças, ambulantes e transeuntes levantam hipóteses sobre o destino daquele homem e desenvolvem estratégias para ajudá-lo. Homem com traje social tira a corda do pescoço e desaparece caminhando em meio à multidão. ${ }^{3}$

Performance e cidade:

o que o corpo pode mover?

Esta é apenas uma dentre tantas outras histórias de performances que parecem compartilhar uma inquietação semelhante: como desdomesticar a relação corpo e cidade? Grosso modo, entendemos que esta domesticação consiste no acionamento das estratégias assépticas, disciplinares e espetaculares que configuram a relação corpo e cidade na contemporaneidade. A título de tatearmos este fenômeno, parece importante evidenciarmos o papel que o chamado fantasma do corpo social desempenha no processo de domesticação dos corpos cotidianos urbanos. Segundo o filósofo francês Michel Foucault, tal assombração possui uma função medicamentosa ao promover
2.

Esta e outras estratégias de escrita presentes neste artigo são livre inspiradas nas proposições da teórica e performer brasileira Eleonora Fabião cujas referências encontram-se ao final do mesmo.

3.

Coletivo Parabelo, Animal Laborans. 2010. São Paulo. Performance.

www.youtube.com/ watch?v=ThjUA3H_474 Acesso em 20/12/2014. 
o anestesiamento dos corpos cotidianos urbanos. Diante do medo de perceberem-se alijados do dito corpo social, os corpos cotidianos urbanos parecem operar em uma espécie de entorpecimento corporal, uma indistinção entre autopreservação e particularização que, no limite, configura a relação corpo e cidade como algo próximo de uma experiência narcótica (SENNET, 2008). Assim, inferimos que são os chamados corpos cotidianos urbanos que atualizam as estratégias que segregam, esquadrinham e desertificam as cidades contemporâneas, por meio da vulgarização da indiferença que varre o espaço urbano cotidianamente. Este desinteresse absoluto pelo outro urbano pode ser lido como índice do que chamaremos aqui de anestética corporal urbana. Isto é, uma forma de embotamento sensório-motor promovido pela sedimentação de uma série de automatismos cognitivos-perceptivos que caracterizam o empobrecimento da experiência corporal urbana.

A anestética corporal urbana consiste na hibridação das estratégias da indiferença, acionadas para salvaguardar os corpos cotidianos urbanos individualmente. De modo que os corpos ditos doentes, delinquentes, vadios, ou seja, os corpos supostamente improdutivos, são expelidos para as margens do espaço urbano devido aos riscos de contágio que estes pretensamente oferecem à saúde do dito corpo social. Desta maneira, a anestética corporal urbana deriva do conjunto de estratégias assépticas, disciplinares e espetaculares que domesticam os corpos cotidianos urbanos conforme arregimentam o chamado corpo social. O próprio Foucault aponta que é somente na supressão de todos os corpos individuais que o corpo social aparece nas sociedades modernas. Isto é, o corpo social não pode ser tomado como a universalização dos corpos cidadãos. Antes disso, o corpo social é configurado pela materialização das estratégias do poder que domesticam, neste caso, os corpos cotidianos urbanos. Logo, se estivermos de acordo que o que estamos chamando aqui de anestética corporal urbana pode ser lida como um índice da domesticação da relação corpo e cidade, qualquer investimento no desmantelamento desta domesticidade, talvez, precise se colocar diante de perguntas como, por exemplo: como tornar o corpo cotidiano urbano sensível à presença do outro nele mesmo? De que modo uma outridade urbana deixaria de representar o contágio da ameaça, ao inaugurar a promessa de outras cidades possíveis?

Se atentarmos para certa genealogia da arte da performance, encontramos desde o final do século XIX performadores interessados em ativar a relação corpo e polis, ao experimentarem uma alteridade radical com o outro urbano através das chamadas errâncias urbanas ${ }^{4}$ (JACQUES, 2012). Seja como uma provocação frente ao processo de modernização das ci-
4.

Flanâncias, visitas dadaístas, deambulações, experiências, derivas, delirium ambulatorium, fluxus walk, manouevres, transurbâncias, zonzos e perfografias são exemplos de errâncias urbanas. 
dades europeias e brasileiras na passagem do século XIX para o século XX, seja como uma denúncia dos regimes ditatoriais que assolaram a América Latina e o Leste Europeu em meados do século XX. Ou então, como um questionamento à estabilização do mercado de arte no eixo Europa-Estados Unidos neste mesmo período e, mais recentemente, como crítica ao processo de gentrificação do espaço público que tenciona a vida urbana neste começo de século XXI. Ao longo dos últimos cem anos, pelo menos, performers podem ser lidos como errantes urbanos, assim como, a performance pode ser entendida como errância urbana.

Desvio, Desvario, Deriva:

- O termo performance é errante. A título de exemplo, em uma rápida consulta ao Google Notícias Brasil, a palavra aparece no cabeçalho de notícias como: Substância usada por Tyson Gay e Powell melhora performance, CEO da Coca-Cola insatisfeito com a performance da empresa, Julho é mês de performance artística no Parque Dona Lindu no Recife, Mulher de Diego Cavalieri elogia performance do marido na cama, Honda lança pacote de performance para o Accord Coupe, ou ainda, Ativistas fazem performance contra consumo de carne de cães na China. Como podemos observar, a palavra performance aparece anexada a uma pluralidade de agentes em contextos diversificados. Embora frisemos que estamos interessados na arte da performance a pergunta "o que é performance?" ainda nos parece uma falsa questão (FABIÃO, 2009). Isto porque esta não pode ser definida com uma única resposta. A performance é indefinível por natureza. Pelo menos no que diz respeito ao campo lexical, a indefinibilidade ainda tem sido a tática de resistência da performance. Contudo, é importante salientarmos que a indefinição do termo não está comprometida com a produção de nenhum tipo de obscurantismo, ou então, com alguma espécie de hermetismo. Pelo contrário. Acreditamos que é justamente através desta resistência a definições prontas que a performance convoca a oxigenação do pensamento. Ao incitar o desmanche dos binarismos que cerceiam, estancam, censuram o ato de pensar, a performance nos convida à experimentação da erraticidade imanente ao pensamento. A própria reflexão parece ser da ordem da errância. Desta forma, ao nos confrontarmos com a pergunta: "Afinal, o que é performance?", convém lembrarmos que a performance é errante e, portanto, avessa às armadilhas que caracterizam as soluções finais. -

Ao errarem para além dos muros das instituições artísticas, performeiros parecem estar interessados em experimentar 
o corpo em deslocamento pela cidade, assim como, a cidade em deslocamento pelo corpo, a fim de testar a emergência do que chamamos de corpo urbano errático (MARQUES, 2013). Ao questionar: o que o corpo pode mover no espaço urbano? Ou ainda, que corpo pode mover na cidade? O corpo urbano errático promove um questionamento ético-político e estético das cidades contemporâneas (FABIÃO, 2008). De acordo com o crítico e curador de arte francês Nicolas Bourriaud, podemos admitir a hipótese de que o corpo urbano errático tem promovido um deslocamento na historiografia da arte deste início de século, semelhante àquele provocado pelo readymade duchampiano nos primórdios do século passado. Isto pois, o corpo urbano errático é aquele que desloca os espaços da artisticidade ao mesmo tempo em que potencializa a politicidade do corpo. Ele emerge como a carne disruptora do fantasma do corpo social, ou seja, como um operador de resistência às estratégias assépticas, disciplinares e espetaculares ativadas pelos corpos cotidianos urbanos. Para tanto, o corpo urbano errático experimenta um corpo a corpo amoroso com a cidade através de uma apreensão sensível do espaço urbano, para aludirmos aos dizeres do filósofo Michel de Certeau, ou dito de outro modo, o performador como errante urbano é aquele que está interessado em investigar a performance como errância urbana como possibilidade de poetizar o urbano, para utilizarmos uma expressão do artista brasileiro Hélio Oiticica.

Performance e Precariedade:

Performances da precariedade

Precariedade da performance

A performance como errância urbana muitas vezes pode ser confundida com um ato de solidariedade na abjeção. Segundo o performeiro mexicano Guillermo Gómez-Peña, o performador como errante urbano se reconhece no olhar daqueles que vivem nas esquinas da sociedade, os chamados órfãos sociais. Gómez-Peña acredita que a performance como errância urbana é um mergulho nos oceanos da miséria na qual nada a população pobre ou em situação de rua. O que marca a diferença entre uns e outros é o nível de profundidade do mergulho na realidade social (2005, p. 210). Não por acaso, ainda de acordo com Guillermo Gómez Penã, a reciclagem seria o principal modo de produção do artista da performance (2005, p.203). Embora o performer como errante urbano erre por vontade própria, este parece emular as práticas daqueles que erram por necessidade, daqueles 
que são soprados para a opacidade pela fantasmagoria do corpo social. A possível associação entre a performance como errância urbana e a reciclagem pode ser lida como uma alusão aos outrora conhecidos como trapeiros e aos quais hoje chamamos de catadores, ou ainda, sucateiros. Corpos anoitecidos que caminham contra os ventos do progresso e amanhecem ao recolher o lixo no qual tropeçam. Corpos cuja materialidade é tida como desimportante, cujas vidas não são consideradas vidas e aos quais a filósofa estadunidense Judith Butler chamou de corpos abjetos.

Ainda que a autora nos ajude a perceber o obscuro, ela o faz com a acuidade de quem sabe que é preciso ser prudente com o excesso de luminosidade, pois esta também costuma ser produtora de invisibilidades. Butler evita oferecer-nos exemplos de corpos abjetos, o que entendemos tratar-se de um determinado cuidado de quem faz ver sem cegar pelas luzes, de um certo esforço para não incluir para excluir aqueles que já padeceriam na exclusão. Contudo, uma conversa com a pesquisadora brasileira Christine Greiner auxilia a testarmos algumas pontes entre os chamados corpos abjetos e o performador como errante urbano. Em seu livro O Corpo em Crise: novas pistas e os curtos-circuitos das representações (2010), Greiner atenta para o fato de que assim como as partes baixas do corpo, as partes baixas das cidades são costumeiramente intocáveis. Em seguida, afirma: "o lúmpen é o abjeto de todas as classes sociais." (GREINER, 2010).

Em uma possível tradução do alemão para o português, lúmpen significa 'homem trapo'. Uma alusão ao termo foi feita por Karl Marx e Friedrich Engels em A Ideologia Alemã (1845), quando os filósofos alemães teriam empregado pela primeira vez o termo lumpemproletariado (2011, p.7o). Para os autores, estes representam uma ameaça para a consciência revolucionária do proletariado e foram descritos por Marx no 18 de Brumário de Luís Bonaparte (1874) como vagabundos, ex-presidiários, saltimbancos, delinquentes, jogadores, tocadores de realejo, escrevinhadores, trapeiros, mendigos, dentre outros. $O$ autor os definia ainda como uma massa indefinida, desintegrada (2011, p. 97). Desta forma, o chamado lumpemproletariado consiste no avesso da fantasmática do corpo social. Os corpos abjetos aos quais evitaríamos perceber, a fim de não encararmos o que eles dizem a respeito de cada um de nós. E, quando surpreendentemente o fazemos, muitas vezes parecemos não nos assustarmos com o reflexo da nossa desumanização. De modo que nos tornamos aqueles que aparentam não ter mais força de estar à altura de nossa fraqueza, uma vez que permanecemos constantemente na fraqueza de cultivar apenas a nossa força (PELBÁRT,2000). 
Outra história de performance

$\mathrm{Ou}$

Outra história pipa,

Outra história solta.

Um homem caminha pela rua e recolhe um lúmpen do chão como um trapo. Coloca-o nos ombros e adentra sala de exposição de um museu de arte moderna. Apoia o corpo abjeto no cubo branco e traça uma linha de sujeira nas paredes. Em seguida, deixa o museu caminhando ao lado do lumpemproletário. ${ }^{5}$

De acordo com a discussão proposta aqui, acreditamos que estes corpos sujos, fétidos e envelhecidos se contrapõem à materialização da idealização do corpo cotidiano urbano. Assim, o performador como errante urbano tece um elogio às performances corporais da precariedade, uma vez que estas configuram uma espécie de triunfo do corpo que instabiliza as estratégias assépticas, disciplinares e espetaculares que domesticam a relação corpo e cidade. Isto é, a performance como errância urbana pode ser lida como uma operadora de resistência ao convocar a possibilidade de criação na escassez. Neste sentido, aquilo que é descartado pelo espectro do corpo social é coletado pelo corpo urbano errático, de forma que este experimenta estes materiais descartáveis encontrados ao acaso pela cidade como extensões corporais. Plástico, papel, compensados, jornais, lata, espumas e arames assumem uma relação de contiguidade com o corpo urbano errático, por meio de um certo embrulhamento corporal. Assim, aquilo que antes foi utilizado geralmente para embalar produtos, ao ser moldado como uma extensão do corpo urbano errático passar a proteger a vida. Ao errar, coletar e reciclar o corpo urbano errático coloca uma questão ética, estética e política para as cidades contemporâneas, ao nos sensibilizar para uma reflexão sobre a multiplicidade de significados imanentes a vitalidade daquilo que é descartável, daqueles que são marginalizados. Através da metamorfose da sobrevivência em forma de existência, os corpos urbanos erráticos transformam o biopoder em biopotência. ${ }^{6}$ Entretanto, a relação de indistinção do corpo urbano errático com esses materiais guarda uma ambiguidade. Nessa proximidade com jornais, sacolas plásticas e papelão, por exemplo, o performeiro como errante urbano aparece desaparecendo na poluição de determinadas paisagens urbanas. De tal modo, o duplo invisibilidade-vulnerabilidade funciona tanto como possibilidade de proteção quanto de exposição às inúmeras formas de violência a qual o dito lumpemproletariado está assujeitado cotidianamente nas cidades contemporâneas.

Contudo, em detrimento de recorrer a temas como os limites corporais, a autobiografia e o pós-humano em busca do risco, Rosemberg Sandoval, Mugre. 1999. Colômbia. Performance. https://www.youtube.com/ watch?v=9T6hNe-ez6Y Acesso em 20/12/2014.

6. Alguns exemplos neste sentido, como as performances Gentrificação (2011/2012) e Catadora de Histórias (2011,) podem ser observadas no site do Coletivo Parabelo www.coletivoparabelo.com 
ou ainda, da liminaridade costumeiramente associada às ações performática, a performance como errância urbana incita uma perda de si mesmo nos espaços da sub-humanização, da caducidade e da precariedade ao camuflar-se em meio aquilo que é excretado, alijado, descartado pelo fantasma do corpo social restos, cacos, detritos. Onde a sociedade do desperdício decreta o fim, o corpo urbano errático urbano emerge como a possibilidade do começo. Ao descentralizar as discussões do âmbito do individual, do econômico e do privado, a performance como errância urbana potencializa o coletivo, o público e o político. Para tanto, o performer como errante urbano investe na precariedade da performance ao desafiar a moral pela depravação, a lógica pelo desvio e o socioeconômico pela vagabundagem, conforme instabiliza a anestética corporal que caracteriza o individualismo urbano ao experimentar uma alteridade radical com uma outro (FABIÃO, 2011). Em alguma instância, inferimos que este escancaramento para a outridade urbana é uma insurgência contra a inoperância do comum que rege a fantasmagoria do corpo social e assombra as sociedades modernas.

Performance e comum:

Mover com

Com mover

Segundo Christine Greiner, podemos entender que o outro é uma impropriedade, ou ainda, aquilo que não é próprio. Desta maneira, é na possibilidade de um escancaramento para o outro que damos a ignição necessária para os processos de comunicação que configuram uma comunidade. Através de uma citação ao filósofo italiano Roberto Espósito, a autora assinala os dois radicais que compõem a etimologia da palavra communitas, termo que significa justamente comunidade em latim. Cum anuncia a presença de um outro além de si, enquanto Munus possui pelo menos três significações: onus, officium e donum, sendo que este último pode ser traduzido como dever, dívida, ou então, obrigação. Logo, uma comunidade não é constituída por nenhuma essência, ou ainda, qualquer substância. A comunidade é um tipo de compromisso no qual um doa-se incondicionalmente ao outro. Neste sentido, a comunidade é um acontecimento no qual a ausência de propriedade, de identidade, de domínio de si expõe as condições de uma política futura. O que há de verdadeiramente comum na comunidade é o munus, ou seja, o comprometimento com o outro (GREINER, 2013). Ainda citando Espósito, Christine Greiner afirma que a experiência da comunidade apresenta a possibilidade de ser arrastado para fora de si como forma de experimentar a vitali- 
dade imanente à irrupção do desconhecido, ao encontro com o inesperado.

Assim, chamamos atenção para o fato de que este extravio de controle sobre si consiste em um princípio ético para o performador como errante urbano. Para ele perder-se também é caminho. A performance como errância urbana consiste justamente nesta arte de extravirar-se de si, de perder-se pelas cidades, de abrir-se para um encontro fortuito com o outro urbano, de modo que talvez possamos ouvir nos passos do corpo urbano errático algo como os murmúrios do comum. Pois, o performer como errante urbano é aquele que desfaz em certa medida a si mesmo, através de uma exposição radical a outridade urbana, ou seja, por meio de uma experimentação de modos de ser em comum. Neste viés, Greiner cita ainda o filósofo Jean-Luc Nancy, de acordo com o qual o Cum é aquilo que nos lança frente a frente com os outros. Investigar a performance como errância urbana exige a experiência de ser com, ou ainda, a necessidade de ser comovido no mais amplo sentido do termo - mover com, com mover, mover-se com o outro (AGRA, 2012).

Portanto, acreditamos que a performance como errância urbana não se enquadra naquilo que as chamadas Arte Cidadã e Arte Pública convencionaram chamar de intervenção urbana, ou em alguns casos, de interferência urbana. Ao invés disso, o performer como errante urbano propõe a realização daquilo que Maria Beatriz de Medeiros chama de Composição Urbana (MEDEIROS, 2008). Para a teórica da performance brasileira, Composições Urbanas implicam na possibilidade de desnormatizar o corpo cotidiano urbano através da instauração de processos nomadizantes, isto é, trajetos poéticos nos quais podemos nos desreificarmos ao nos tornarmos errantes, conforme transfazemos os caminhos do outro. Composições Urbanas instabilizam a primazia do sentido da visão que nos orienta pelo espaço urbano, através da experimentação de alterações de estados corporais ao afetarmos e sermos afetados no corpo a corpo com a cidade. Para além de um debate terminológico, o que parece estar em jogo no uso do conceito de Composição Urbana é a tentativa de tirar a questão da alteridade da sombra da cidadania. De forma que a diferença não se coloque apenas como um axioma democrático, à medida que a performance como errância urbana seja o exercício de uma paixão pela incerteza criadora, no qual a diferença esteja comprometida com a alteridade necessária para a produção de singularidade. (ROLNIK, 2014). Nestes casos, trata-se daquilo que o filósofo italiano Giorgio Agamben chamou de singularidade qualquer. Performances como errâncias urbanas são manifestações singulares, manifestações do qual-quer, uma vez que estas 
abrem mão de qualquer representatividade, de qualquer identidade, de qualquer território, para se constituírem nos fluxos de alteridade produtora de singularidades. Performers como errantes urbanos podem aparecer desaparecendo em qualquer lugar, a qualquer hora, podem ser qualquer um. Deste modo, as singularidades quaisquer podem ser entendidas como linhas de fuga diante da ação do poder instituído, ao denunciarem a crise da política representativa moderna (AGAMBEN apud GREINER, 2013).

O performador como errante urbano é aquele que exercita um certo desmanchamento de si com a prudência necessária daquele que se compõe, decompõe e recompõe sempre em correlação com o outro urbano. Portanto, a performance como errância urbana desmantela a noção de um sujeito que dispõe de uma metodologia para agir sobre um objeto. Ao contrário. Ela propõe uma inversão dos entendimentos convencionais de metodologia, uma vez que ela pressupõe um hodós metá em detrimento de um método propriamente dito, ou seja, como não há um caminho dado a priori, a performance como errância urbana se configura como um caminho que só se faz caminhando. Através dos movimentos de territorialização, desterritorialização e reterritorialização imanentes a qualquer errância, o performador como errante urbano executa um árduo exercício sobre si ao testar incessantemente modos de se pôr com, de com pôr com o outro: o outro em si, o outro urbano. Por último, mas não mesmo importante, gostaríamos de esboçar uma questão. Para além dos legítimos pressupostos ativistas que parecem pautar as discussões em torno da relação corpo, performance e cidade, o performeiro como errante urbano e a performance como errância urbana parecem anunciar a possibilidade de um afetivismo. Nestes tempos em que somos mobilizados pelo medo, pelo ressentimento e pela indiferença que tonificam nossa anestética corporal urbana, compartilhamos aqui uma inquietação: se a política pode ser entendida como a arte de afetar os corpos, um dos desafios políticos do nosso tempo não seria nos lançarmos na errância imprescindível para a retivalização dos nossos afetos? (SAFATLE, 2013). Perder o sentido, para abrir os sentidos. 
AGRA, Lúcio. Performance e alteridade. Texto inédito apresentado na IV Semana de Estudos Teatrais - Urdiduras da Performance, UNESP, São Paulo, 2 de julho de 2012.

AQUINO, F.M.; AZAMBUJA, D.; MEDEIROS, M. B. Composição Urbana (CU) e Ueb arte iterativa (UAI): práticas e teorias artísticas do Corpos Informáticos. In: Anais do $17^{\circ}$ ANPAP (Encontro da Associação Nacional de Pesquisadores em Artes Plásticas), Florianópolis/SC, 2008, p. 1888-1897.

BOURRIAUD, Nicolas. Radicante: por uma estética da globalização. São Paulo: Martins Fontes, 2011.

FABIÃO, Eleonora. Performance e precariedade. In OLIVEIRA JUNIOR, Antonio Wellington de (Org.). A performance ensaiada: ensaios sobre performance contemporânea. Fortaleza: Expressão Gráfica e editora, 2011, p. 63-85.

Performance e teatro: poéticas e políticas

da cena contemporânea. In Sala Preta, Revista de Artes Cênicas, no 8, p. 235-246. São Paulo: Departamento de Artes Cênicas, ECA/ USP, 2008.

FOUCAULT, Michel. Microfísica do Poder. São Paulo: Graal, 2012.

GAGNEBIN, Jeanne Marie. Lembrar escrever esquecer. São Paulo: Ed. 34, 2006.

GÓMEZ-PEÑA, Guillermo. En defensa del arte del performance. In: Horizontes Antropológicos, Porto Alegre, ano 11, n. 24, p. 199-226, jul./dez. 2005.

GREINER, Christine. O corpo em Crise: Novas Pistas e o Curto Circuito das Representações. Ed: Annablume. São Paulo, 2010.

Performance e o risco da inope-

rância do comum. In TEIXEIRA, A. (Org). A cozinha performática. São Paulo: Árvore da Terra, 2013.

JACQUES, Paola Berenstein. Elogio aos errantes. Salvador: EDUFBA, 2012.

MARQUES, Diego. Errar/Performar: performador como errante, performance como errância. Pesquisa de Iniciação Científica pelo curso de Comunicação das Artes do Corpo da PUC/SP, subsidiada pela PIBIC-CEPE, 2013.

MARX, Karl Heinrich. O 18 de Brumário de Luís Bonaparte. Trad. Nélio Schneider. São Paulo: Boitempo, 2011.

MARX, Karl Heinrich; ENGELS, Friedrich. A ideologia alemã: crítica da mais recente filosofia alemã em seus representantes Feuerbach, B. Bauer e Stirner, e do socialismo alemão em seus diferentes profetas (1845-1846). Trad. Rubens Enderle, Nélio Schneider, Luciano C. Martorano. São Paulo: Boitempo, 2007. 
PELBART, Peter Pál. Vida capital: ensaios de biopolítica. São Paulo: Iluminuras, 2000.

PRINS, Baukje; MEIJER, Irene Costera. Como os corpos se tornam matéria: entrevista com Judith Butler. Revista Estudos Feministas. Trad. Susana Bornéo Funck, vol. 10, $\mathrm{n}^{\circ} 1$. Florianópolis: UFSC. Janeiro de 2002.

ROLNIK, Suely. À sombra da cidadania: alteridade, homem da ética e reinvenção da democracia. Artigo disponível em: dev. nucleodesubjetividade.net/o.4/wpcontent/.../og/homemetica. pdf. Acesso em: 20 de dezembro de 2014.

SAFATLE, Vladimir. Uma política dos afetos. In Folha de São Paulo, artigo publicado em of de janeiro de 2014.

SENNET, Richard. Carne e Pedra: o corpo e a cidade na civilização ocidental. Trad. Marcos Aarão Reis, Rio de Janeiro: Record, 2010. 